\author{
Melis ÇERÇIOĞLU1 \\ Bülent YAĞMUR² \\ Recep Serdar KARA² \\ Bülent OKUR2
}

\section{Agro-Endüstriyel Kompost ve Ahır Gübresinin Biber (Capsicum annuum L.) Yetiştiriciliğinde Toprağın Bazı Kimyasal Özellikleri ile Verim Üzerine Etkisi}

\author{
The Effect of Agro-Industrial Compost and Farmyard Manure \\ on Some Chemical Properties of Soil and Yield of Grown \\ Pepper (Capsicum annuum L.)
}

${ }^{2}$ Ege Üniversitesi, Ziraat Fakültesi, Toprak Bilimi ve Bitki Besleme Bölümü, 35100, İzmir / Türkiye sorumlu yazar: melis.cercioglu@dpu.edu.tr

Anahtar Sözcükler:

Ahır gübresi, Capsicum annuum L., kompost, toprağın kimyasal özellikleri

Key Words:

Farmyard manure, Capsicum annuuum L., compost, soil chemical properties
Alını̧ (Received): 19.09.2016 Kabul tarihi (Accepted): 31.10 .2016

\begin{abstract}
This research was conducted to investigate the effect of composted greenhouse residues and farmyard manure on some chemical properties $(\mathrm{pH}, \mathrm{EC}, \mathrm{OM}$ $\mathrm{CaCO}_{3}, \mathrm{CEC}$ ) of soil and pepper (Capsicum annuum L.) yield. The study was held between the years of 2014-2015 in the greenhouses of Vocational College of Simav of Dumlupinar University in Simav district of Kutahya according to randomized block design in $6 \mathrm{~m}^{2}(3 \times 2)$ plots with three replications. Treatments were as follows: (1) NPK, (2) $4 \mathrm{t} \mathrm{da}^{-1}$ farmyard manure +NPK, (3) $4 \mathrm{t} \mathrm{da}^{-1}$ compost+NPK, (4) $8 \mathrm{t} \mathrm{da}^{-1}$ compost+NPK, (5) control, (6) $4 \mathrm{t} \mathrm{da}^{-1}$ compost, (7) $4 \mathrm{t} \mathrm{da}^{1}$ animal manure, (8) $8 \mathrm{t} \mathrm{da}^{-1}$ compost. In the experiment, animal manure and greenhouse redidues applied to the soil obtained from Eynal region of Simav. In consequence of research, (2) $4 \mathrm{t} \mathrm{da}^{-1}$ animal manure+NPK, (4) $8 \mathrm{t} \mathrm{da}^{-1}$ compost+NPK ve (6) $4 \mathrm{t} \mathrm{da}^{-1}$ compost were determined as the most effective treatments on chemical properties of soil and pepper yield.
\end{abstract}

\section{GíRiş}

Bitkisel üretimde birim alandan daha fazla ürün alınabilmesi amacıyla yapılan yoğun ve bilinçsiz kimyasal gübreleme tuzluluk, sıkışma, toprak yorgunluğu ve organik madde miktarının azalması gibi olumsuz sonuçlara yol açabilmektedir (Erkoç, 2009).
Ülkemiz koşullarında organik madde içeriği, toprağın üretkenlik kapasitesini etkileyen önemli bir parametredir. Ülkemizde en önemli organik madde kaynağı ahır gübresidir (Bayındır ve ark., 2004). Ahır gübresinin gerekli miktarda, uygun periyod ve yeterli olgunlukta bulunamaması yetiştiriciyi başka arayışlara yöneltmektedir. Bu durum organik madde kaynağı 
olarak atık materyallerin tarımsal alanlarda kullanımının önemini açığa çıkarmaktadır (Özgüven ve ark., 1996). Sera topraklarındaki organik madde eksikliğinin ahır gübresi, torf ve kompost gibi materyaller kullanılarak giderilebileceği belirtilmektedir (Tüzel ve ark., 1992; Tüzel, 1996). Hasattan sonra geriye kalan bitkisel artıklar, çiftlik artıkları, ahır gübreleri, kentsel artıklar, sanayi atıkları ve benzeri materyaller doğrudan veya kompostlaştırıldıktan sonra toprakların organik madde içeriğini arttırmak için kullanılabilmektedir (Entry et al., 1997; Pascual et al., 1997; Madejon et al., 2001; Kütük ve ark., 2003; Bhattacharyya et al., 2003).

Son yıllarda çevresel kirliliğin önlenmesi ve atıkların değerlendirilmesi amacıyla bitkisel üretim sonucunda oluşan hasat atıklarının veya hammaddesi tarımsal ürün olan pek çok fabrikasyon atığının tarımsal üretimde girdi olarak kullanılması yaygınlaşmışıı. Böylece tarımsal üretimle elde edilen ürünlerin işlenmesinden arta kalan materyallerin tekrar ayn alanlarda kullanımı ile çevre üzerine olan olumsuz etkilerinin azaltılması sağlanmıştır. Bugün yapılan pek çok çalışma, atık olarak nitelendirilen çoğu materyalin topraklara direkt ilavesi ile organik madde ve bitki besin maddesi kaynağı olabileceğini veya belli oranlarda karışımlar ile yetiştirme ortamı olarak kullanılabileceğini göstermiştir (Aydeniz ve Brohi, 1991; Özenç, 2004; Benito et al., 2005; Benito et al., 2006).

Bitki atıklarının toprağa uygulanması; topraktaki mikrobiyal faaliyetlerin, bitki besin elementlerinin mineralizasyonu ile teşvik edildiği (Eriksen, 2005; Randhawa et al., 2005) ve toprak verimliliğini, kalitesini arttırdığı (Doran et al., 1987) için iyi bir yönetim uygulaması olarak kabul edilmektedir.

Ülkemizde son yıllarda giderek artış gösteren seracilıkta birim alandan daha fazla ürün elde etmek amaçlanmaktadır. Bu nedenle birim alanda yetiştirilen bitki sayısı ve elde edilen biyokütle ağırlıkları fazladır (Çıtak ve ark., 2006). Domates gibi yüksek değerli sebze bitkilerinden kompost uygulaması, çayır ve çimlerden elde edilen kompost uygulamasından daha ekonomik ve pratik olabilmektedir (Roe and Cornforth, 2000).

Bu çalışmada Kütahya'nın Simav ilçesindeki sera bölgesinden toplanan hasat atıklarının (domates) kompost haline getirilerek ahır gübresi ile beraber toprağın $\mathrm{pH}$, elektriksel iletkenlik, kireç, organik madde ve katyon değişim kapasitesi gibi kimyasal özellikleri ile biber verimi üzerine olan etkileri incelenmiş ve uygun kullanım dozları belirlenmiştir.

\section{MATERYAL ve YÖNTEM}

Bu çalışma, 2014-2015 yılları arasında, Kütahya'nın Simav ilçesi Eynal bölgesinde bulunan Dumlupınar Üniversitesi Simav Meslek Yüksekokulu'na ait serada iki yıllık bir deneme olarak gerçekleştirilmiştir. Deneme toprağının özellikleri Çizelge 1'de verilmiştir. Kompost ve ahır gübresi materyalleri tesadüf blokları deneme desenine göre $6 \mathrm{~m}^{2}$ lik $(3 \mathrm{~m} \times 2 \mathrm{~m})$ parsellere üç tekrarlı olarak uygulanmıştır. Toplam parsel sayısı 24 'dür. Denemeye ait uygulamalar; (1) NPK, (2) $4 \mathrm{t} \mathrm{da}^{-1}$ ahır gübresi+NPK, (3) $4 \mathrm{t} \mathrm{da}^{-1}$ kompost+NPK, (4) $8 \mathrm{t} \mathrm{da}^{-1}$ kompost+NPK, (5) Kontrol, (6) $4 \mathrm{t} \mathrm{da}^{-1}$ kompost, (7) $4 \mathrm{t}$ $\mathrm{da}^{-1}$ ahır gübresi, (8) $8 \mathrm{t} \mathrm{da}^{-1}$ kompost olarak belirlenmiştir.

Çizelge 1. Deneme alanına ait toprağın fiziksel ve kimyasal özellikleri Table 1. Physical and chemical properties of experimental soil

\begin{tabular}{|c|c|}
\hline Bünye & Kumlu Tın \\
\hline Kum (\%) & 60.48 \\
\hline Mil (\%) & 27.64 \\
\hline Kil (\%) & 10.88 \\
\hline pH & 7.71 \\
\hline $\mathrm{EC}(\mu \mathrm{S} / \mathrm{cm})$ & 1467 \\
\hline $\mathrm{CaCO}_{3}(\%)$ & 1.80 \\
\hline OM (\%) & 1.85 \\
\hline Toplam N (\%) & 0.17 \\
\hline Alınabilir P (mg kg-1) & 104.6 \\
\hline Alınabilir K (me $100 \mathrm{~g}^{-1}$ ) & 0.52 \\
\hline Alınabilir Ca (me $100 \mathrm{~g}^{-1}$ ) & 18.8 \\
\hline Alınabilir Mg (me $100 \mathrm{~g}^{-1}$ ) & 7.02 \\
\hline Alınabilir $\mathrm{Na}$ (me $100 \mathrm{~g}^{-1}$ ) & 0.92 \\
\hline Alınabilir Fe (mg kg-1) & 7.98 \\
\hline Alınabilir $\mathbf{M n}\left(\mathbf{m g ~ k g}^{-1}\right)$ & 10.10 \\
\hline Alınabilir $\mathrm{Cu}\left(\mathrm{mg} \mathrm{kg}^{-1}\right)$ & 2.15 \\
\hline Alınabilir Zn ( $\left.\mathrm{mg} \mathrm{kg}^{-1}\right)$ & 3.92 \\
\hline
\end{tabular}

Simav ilçesindeki Eynal bölgesinde bulunan seralardan elde edilen sera atıkları (domates) kompostlaştııılıktan sonra üreticilerden alınan olgunlaşmış ahır gübresi ile birlikte parsellere uygulanmıştır. Denemede kullanılan ahır gübresi ile kompostun özellikleri Çizelge 2'de verilmiştir.

Çizelge 2. Denemede kullanılan kompost ve ahır gübresinin özellikleri Table 2. Compost and farmyard manure properties used in the experiment

\begin{tabular}{|c|c|c|}
\hline & Kompost & Ahır gübresi \\
\hline pH & 8.79 & 8.43 \\
\hline$E C\left(\mu S \mathrm{~cm}^{-1}\right)$ & 1772 & 2700 \\
\hline OM (\%) & 30 & 57.8 \\
\hline C:N & 7.99 & 14.2 \\
\hline Toplam N (\%) & 2.18 & 2.35 \\
\hline Toplam P (\%) & 0.13 & 0.36 \\
\hline Toplam Ca (\%) & 1.15 & 2.42 \\
\hline Toplam K (mg kg $\left.{ }^{-1}\right)$ & 5547 & 9400 \\
\hline Toplam Mg (mg kg-1) & 2469 & 5300 \\
\hline Toplam Na (mg kg-1) & 481.2 & 588 \\
\hline Toplam Fe (mg kg ${ }^{-1}$ ) & 5964 & 784 \\
\hline Toplam Mn (mg kg-1) & 254 & 202 \\
\hline Toplam Cu (mg kg $\left.{ }^{-1}\right)$ & 10.6 & 12.3 \\
\hline Toplam Zn (mg kg ${ }^{-1}$ ) & 45.5 & 51.6 \\
\hline
\end{tabular}


Denemenin gerçekleştiği toprakta $8.5 \mathrm{~kg} \mathrm{da}^{-1} \mathrm{~N}$, $18.04 \mathrm{~kg} \mathrm{da}^{-1} \mathrm{P}_{2} \mathrm{O}_{5}$ ve $20.28 \mathrm{~kg} \mathrm{da}^{-1} \mathrm{~K}_{2} \mathrm{O}$ (azotun ilk yıl $\% 40^{\prime}$; ; fosforun \%30'u ve potasyumun \%40'ı dikkate alındığında) analiz edilmiştir. Biber bitkisi 1 ton ürünle topraktan $7 \mathrm{~kg} \mathrm{~N}, 1.60 \mathrm{~kg} \mathrm{P}_{2} \mathrm{O}_{5}$ ve $7 \mathrm{~kg} \mathrm{~K}_{2} \mathrm{O}$ kaldırmaktadır. Akdeniz Bölgesi koşullarında 1 dekar alanda yapılan biber yetiştiriciliğinde, vejetatif aksam üretimi için $9 \mathrm{~kg}$ azot, $0.6 \mathrm{~kg}$ fosfor ve $9 \mathrm{~kg}$ potasyum ve 1 ton meyve üretimi için ise $2 \mathrm{~kg}$ azot, $0.26 \mathrm{~kg}$ fosfor, $1.83 \mathrm{~kg}$ potasyum gerekli olduğu bildirilmiştir (Röber and Schaller, 1985).

Çalışmada kullanılan materyallerin de bitki besin elementi analizleri yapılmış ve elde edilen verilere göre bazı uygulamalarda takviye olarak mineral gübre ilave edilmiştir. Mineral gübre olarak; mono amonyum fosfat, potasyum sülfat, amonyum nitrat, potasyum nitrat ve kalsiyum nitrat gübreleri kullanılmıştır.

Denemede test bitkisi olarak, sivri biber (Capsicum annuum L.) kullanılmıştır. Biber bitkisi (Capsicum annuum L.), ülkemizde tarım alanları için potansiyel bir risk olan tuzluluk sorununun yaygın olarak görüldüğü kurak ve yarı kurak birçok bölgede, açıkta ve örtü altında yetiştiriciliği yapılan en önemli sebzelerden biridir. 2015 yılındaki örtü altı sivri biber üretimimiz 385548 ton olarak belirlenmiştir (TÜiK, 2016).

İki vejetasyon dönemi içerisinde gerçekleşen araştırmada, her vejetasyonda iki toprak örneği (dikim ve hasat dönemleri) alınarak toplam dört adet örnekleme yapılmıştır. Çalışmanın deneysel analizleri Ege Üniversitesi Ziraat Fakültesi Toprak Bilimi ve Bitki Besleme Bölümü laboratuvarlarında yapılmıştır. Laboratuvarda hava kurusu haline getirilen toprak örnekleri, $2 \mathrm{~mm}$ 'lik elekten geçirildikten sonra analizlerde kullanılmak üzere hazır hale getirilmiştir (Soil Survey Staff, 1951). Toprakların dane büyüklüğü dağılımı yani \% kum, \% mil ve \% kil fraksiyonları hidrometre yöntemi uygulanarak belirlenmiştir (Bouyoucos, 1962). Her fraksiyon için bulunan veriler bünye üçgenine uygulanarak toprak örneklerinin bünyeleri belirlenmiştir (Black, 1965). Toprak pH'sı, sature toprak macununda cam elekrotlu $\mathrm{pH}$-metre ile belirlenmiştir (Jackson, 1967). Toprağın elektriksel iletkenliği (EC) U.S.Salinity Lab. Staff'a göre cam elektrotlu EC-metre ile analiz edilmiştir (U.S. Salinity Lab. Staff., 1954). Kireç yüzdesi $\left(\% \mathrm{CaCO}_{3}\right)$ Scheibler kalsimetresi ile analiz edilmiştir (Tüzüner, 1990). Organik madde, Modifiye Walkley-Black yöntemine göre belirlenmiştir (Nelson and Sommer, 1982). Toprak örneklerinin toplam azot miktarları modifiye makro Kjeldahl yöntemi ile, alınabilir $\mathrm{Na}, \mathrm{K}, \mathrm{Ca}$, Mg değerleri $\mathrm{pH}$ değeri 7 olan $1 \mathrm{~N} \mathrm{NH}_{4} \mathrm{OAc}$ ile çalkalanarak elde edilen süzüklerde $\mathrm{Na}, \mathrm{K}, \mathrm{Ca}$ değerlerini fleymfotometrede, Mg değerleri ise atomik absorbsiyon spekrofotometresinde tayin edilmiştir (Kacar, 1995). Toprak örneklerinin alınabilir fosfor miktarları Olsen yöntemine göre kolorimetrik olarak tayin edilmiştir (Olsen and Sommers, 1982). Toprakların alınabilir Fe, $\mathrm{Cu}, \mathrm{Zn}, \mathrm{Mn}$ değerleri $20 \mathrm{~g}$ hava kurusu toprak örneğinin $40 \mathrm{ml}$ DTPA $+\mathrm{CaCl}_{2}+$ TEA ile çalkalanıp süzülmesi sonucu atomik absorbsiyon spektrofotometrede okunarak belirlenmiştir (Lindsay and Norvell, 1978).

Araştırmada biber bitkisinin su isteğine göre tarla kapasitesindeki su miktarının \%70'inin altına düşülmeyecek şekilde damla sulama sistemi kullanılarak sulama yapılmıştır. Her parselden hasat edilen biber bitkileri, her hasatta tartılarak yaş ağırlıkları belirlenmiş ve daha sonra toplam verimler parsel alanı üzerinden $\mathrm{kg}$ $\mathrm{da}^{-1}$ olarak hesaplanmıştır. Illk hasat başladıktan sonra haftada bir kez hasat yapılmıştır. Araştırmadan elde edilen sonuçlar ise varyans analizi (ANOVA) ve Tukey testi gibi istatistiksel yöntemler yardımı ile analiz edilmiştir. Bu analizler Minitab 16 ve SPSS 21 yazılımları kullanılarak gerçekleştirilmiştir.

\section{ARAŞTIRMA BULGULARI ve TARTIŞMA}

\section{Toprağın Kimyasal Özellikleri}

Uygulamalar öncesi deneme toprağının pH'sı 7.71 olarak analiz edilmiştir. Bütün uygulama dozlarının toprak örneklerinin $\mathrm{pH}$ 'sı üzerine etkisi istatistiksel olarak önemli bulunmuştur $(p<0.05)$. Kompost ve ahır gübresi uygulamaları ile bu değer 7.70 ile 7.85 arasında bir değişim göstermiştir. Toprağa uygulanan farklı organik materyaller kontrol parseline göre toprağın $\mathrm{pH}$ değerlerinde çok az (\%1.9) bir artış sağlamış ve hafif alkali (7.4-7.8) sınırları içinde kalmıştır (Kellogg, 1952). Biber bitkisi yetiştiriciliğinde toprak pH'sının 6.0-6.5 arasında olması istenir (Duman, 2005). Maksimum $\mathrm{pH}$ değerleri $4 \mathrm{t} \mathrm{da}^{-1}$ kompost ile 6 numaralı uygulamadan belirlenmiştir (Çizelge 3 ). Denemede kullanılan sera atığı kompostu (8.79) ve ahır gübresi (8.43) materyallerinin yüksek pH'ya sahip olmalarından dolayı toprak pH'sında bir miktar artış olması beklenen bir sonuç olup bitki beslenmesi açısından herhangi bir olumsuzluk yaratmamıştır.

Kompost ve ahır gübresi uygulamalarıyla toprakların elektriksel iletkenlik (EC) değerlerinde artış olmuş ve 1457 ile $1493 \mu \mathrm{S} \mathrm{cm}^{-1}$ arasında değişen değerler elde edilmiştir. En yüksek tuzluluk değerleri $4 \mathrm{t} \mathrm{da}^{-1}$ ahır gübresi+NPK parsellerinde analiz edilmiştir. Kompostun EC değeri $1772 \mu \mathrm{S} \mathrm{cm}^{-1}$; ahır gübresinin ise $2700 \mu \mathrm{S} \mathrm{cm}^{-1}$ olarak belirlenmiş ve bu atıkların uygulamasıyla tuzsuz olan deneme alanının tuz içeriği çok az miktarda artmış ve tuzsuz (0-2000 $\mu \mathrm{S} \mathrm{cm}^{-1}$ ) sınıfına (USDA, 2002) girmiştir (Çizelge 4). 
Çizelge 3. Uygulamaların birinci ve ikinci vejetasyon dönemlerinde alınan toprak örneklerinin pH değerleri üzerine etkisi (Tukey testi, p $\leq 0.05$ ). Table 3. Impact of treatments on $\mathrm{pH}$ values of first and second vegetation soil samples (Tukey's test, p $\leq 0.05$ ).

\begin{tabular}{|c|c|c|}
\hline \multirow{2}{*}{ Uygulamalar } & \multicolumn{2}{|c|}{ pH } \\
\hline & I. Vejetasyon & II. Vejetasyon \\
\hline 1 (NPK) & $7.74 \mathrm{~d}$ & $7.71 \mathrm{~d}$ \\
\hline 2 (4 t da-1 ahır gübresi+NPK) & $7.72 \mathrm{~d}$ & $7.71 \mathrm{~d}$ \\
\hline 3 (4t da ${ }^{-1}$ kompost+NPK) & $7.80 \mathrm{c}$ & $7.77 \mathrm{c}$ \\
\hline 4 (8 t da ${ }^{-1}$ kompost+NPK) & $7.82 \mathrm{~b}$ & $7.78 \mathrm{bc}$ \\
\hline 5 (Kontrol) & $7.70 \mathrm{e}$ & $7.70 \mathrm{~d}$ \\
\hline 6 (4 t da ${ }^{-1}$ kompost) & $7.85 \mathrm{a}$ & $7.83 \mathrm{a}$ \\
\hline 7 (4 t da-1 ahır gübresi) & $7.81 \mathrm{bc}$ & $7.78 \mathrm{bc}$ \\
\hline 8 (8 t da ${ }^{-1}$ kompost) & $7.82 \mathrm{~b}$ & $7.79 \mathrm{~b}$ \\
\hline
\end{tabular}

Çizelge 4. Uygulamaların birinci ve ikinci vejetasyon dönemlerinde alınan toprak örneklerinin EC değerleri üzerine etkisi (Tukey testi, p $\leq 0.05)$. Table 4. Impact of treatments on EC values of first and second vegetation soil samples (Tukey's test, p $\leq 0.05$ ).

\begin{tabular}{|c|c|c|}
\hline \multirow{2}{*}{ Uygulamalar } & \multicolumn{2}{|c|}{$E C\left(\mu S \mathrm{~cm}^{-1}\right)$} \\
\hline & I. Vejetasyon & II.Vejetasyon \\
\hline 1 (NPK) & $1476 \mathrm{f}$ & $1471 \mathrm{~d}$ \\
\hline 2 (4 t da-1 ahır gübresi+NPK) & 1493 a & $1488 a$ \\
\hline 3 (4 t da ${ }^{-1}$ kompost+NPK) & $1483 \mathrm{~d}$ & $1478 b$ \\
\hline $4\left(8 \mathrm{t} \mathrm{da}^{-1}\right.$ kompost+NPK) & $1485 c$ & $1479 \mathrm{~b}$ \\
\hline 5 (Kontrol) & $1465 \mathrm{~g}$ & $1457 \mathrm{e}$ \\
\hline 6 (4 t da ${ }^{-1}$ kompost) & $1481 \mathrm{e}$ & $1474 \mathrm{c}$ \\
\hline 7 (4 t da-1 ahır gübresi) & $1489 \mathrm{~b}$ & $1480 \mathrm{~b}$ \\
\hline 8 (8 t da ${ }^{-1}$ kompost) & $1481 \mathrm{e}$ & $1473 \mathrm{~cd}$ \\
\hline
\end{tabular}

Toprağın organik madde içeriği farklı uygulamalar sonucunda \%1.48 ile 4.36 arasında değişim göstermiştir. Kontrol parsellerine göre toprağın organik madde içeriği yaklaşık olarak \%184'lik belirgin bir artış göstermiştir. Birinci ve ikinci vejetasyon dönemlerindeki en yüksek organik madde miktarları $4 \mathrm{t} \mathrm{da}^{-1}$ ahır gübresi+NPK uygulamalarında belirlenmiştir (Çizelge 5). Çalışmada kullanılan materyallerden kompostun organik madde içeriği \%30; ahır gübresinin ise \%57.8 olarak analiz edildiğinden bu materyallerin uygulanması ile toprağın organik madde içeriğinde artışların gözlenmesi olumlu yöndedir. Toprak örneklerinin organik madde içeriği (Walkley-Black yöntemine) \%4-8 arasında analiz edildiği için organik madde yönünden zengin olarak sınıflandırılmaktadır (Nelson and Sommer, 1982).

Çizelge 5. Uygulamaların birinci ve ikinci vejetasyon dönemlerinde alınan toprak örneklerinin OM içeriği üzerine etkisi (Tukey testi, $\mathrm{p} \leq 0.05)$. Table 5. Impact of treatments on OM content of first and second vegetation soil samples (Tukey's test, $p \leq 0.05$ )

\begin{tabular}{lcc}
\hline \multirow{2}{*}{ Uygulamalar } & & OM (\%) \\
\cline { 2 - 3 } & I.Vejetasyon & II.Vejetasyon \\
\hline 1 (NPK) & $1.82 \mathrm{f}$ & $1.55 \mathrm{e}$ \\
$2\left(4 \mathrm{t} \mathrm{da}^{-1}\right.$ ahır gübresi+NPK) & $4.36 \mathrm{a}$ & $4.20 \mathrm{a}$ \\
$3\left(4 \mathrm{t} \mathrm{da}^{-1}\right.$ kompost+NPK) & $4.03 \mathrm{~d}$ & $3.84 \mathrm{c}$ \\
$4\left(8 \mathrm{t} \mathrm{da}^{-1}\right.$ kompost+NPK) & $4.09 \mathrm{c}$ & $4.02 \mathrm{~b}$ \\
$5\left(\mathrm{Kontrol}^{-1}\right.$ & $1.80 \mathrm{f}$ & $1.48 \mathrm{f}$ \\
$6\left(4 \mathrm{t} \mathrm{da}^{-1}\right.$ kompost) & $3.54 \mathrm{e}$ & $3.34 \mathrm{~d}$ \\
$7\left(4 \mathrm{t} \mathrm{da}^{-1}\right.$ ahır gübresi) & $4.32 \mathrm{~b}$ & $4.19 \mathrm{a}$ \\
$8\left(8 \mathrm{t} \mathrm{da}^{-1}\right.$ kompost) & $4.10 \mathrm{c}$ & $3.98 \mathrm{~b}$ \\
\hline
\end{tabular}

Kompost ve ahır gübresi ilaveleriyle topraktaki \% $\mathrm{CaCO}_{3}$ miktarı \%1.16 ile 3.17 arasında değişim göstermiştir (Çizelge 6). En yüksek kireç miktarı ise $\% 3.17$ değeri ile birinci vejetasyon döneminde alınan ve $8 \mathrm{t} \mathrm{da}^{-1}$ kompost uygulamasının yapıldığı parselden elde edilmiştir. Toprağa uygulanan farklı organik materyaller kontrol parsellerine göre toprağın kireç içeriğinde $\% 143^{\prime} \mid u ̈ k$ bir artış göstermiştir. Denemede kullanılan kompost (8.79) ile ahır gübresinin (8.43) pH'larının yüksek olmasından dolayı toprakların kireç miktarının artması beklenen bir sonuçtur.

Toprakların katyon değişim kapasitesi (KDK) değerleri, kompost ve ahır gübresi uygulamaları sonucu istatistiksel olarak $(p<0.05)$ önemli bulunmuştur (Çizelge 7). 3 ve 6 numaralı uygulamalar ile 4 ve 7 numaralı uygulamalar arasında istatistiksel 
olarak fark bulunmaz iken, $8 \mathrm{t} \mathrm{da}^{-1}$ kompost uygulamasının yapıldığı toprak örneklerinde en yüksek KDK değerleri belirlenmiştir. Kontrol parsellerine göre meydana gelen artış oranı en fazla $\% 12$ ile birinci vejetasyonda 8 numaralı uygulamadan 2.87 me $100 \mathrm{~g}^{-1}$ olarak analiz edilmiştir. Organik madde ile KDK arasında pozitif bir ilişki olduğu bilinmektedir. Topraktaki organik madde miktarı arttıkça katyon değişim kapasitesinin artması beklenen bir gelişmedir. Denemede kullanılan kompost (\%30) ve ahır gübresinin (\%57.8) içerdikleri OM değerlerinin bu artışı sağlamada etkisi büyüktür.

Çizelge 6. Uygulamaların birinci ve ikinci vejetasyon dönemlerinde alınan toprak örneklerinin $\mathrm{CaCO}_{3}$ içeriği üzerine etkisi (Tukey testi, $\mathrm{p} \leq 0.05$ ). Table 6. Impact of treatments on $\mathrm{CaCO}_{3}$ content of first and second vegetation soil samples (Tukey's test, p $\left.\leq 0.05\right)$.

\begin{tabular}{lcc}
\hline \multirow{2}{*}{ Uygulamalar } & & CaCO $_{\mathbf{3}}$ (\%) \\
\cline { 2 - 3 } 1 (NPK) & I. Vejetasyon & $2.03 \mathrm{ab}$ \\
$2\left(4 \mathrm{t} \mathrm{da}^{-1}\right.$ ahır gübresi+NPK) & $1.33 \mathrm{c}$ & $1.33 \mathrm{bc}$ \\
$3\left(4 \mathrm{t} \mathrm{da}^{-1}\right.$ kompost+NPK) & $1.30 \mathrm{c}$ & $1.56 \mathrm{abc}$ \\
$4\left(8 \mathrm{t} \mathrm{da}^{-1}\right.$ kompost+NPK) & $2.20 \mathrm{~b}$ & $1.83 \mathrm{abc}$ \\
$5\left(\mathrm{Kontrol}^{\prime}\right)$ & $3.13 \mathrm{a}$ & $1.30 \mathrm{bc}$ \\
$6\left(4 \mathrm{t} \mathrm{da}^{-1}\right.$ kompost) & $1.47 \mathrm{c}$ & $2.23 \mathrm{a}$ \\
$7\left(4 \mathrm{t} \mathrm{da}^{-1}\right.$ ahır gübresi) & $2.43 \mathrm{~b}$ & $1.16 \mathrm{c}$ \\
$8\left(8 \mathrm{t} \mathrm{da}^{-1}\right.$ kompost) & $1.43 \mathrm{c}$ & $1.90 \mathrm{abc}$ \\
\hline
\end{tabular}

Çizelge 7. Uygulamaların birinci ve ikinci vejetasyon dönemlerinde alınan toprak örneklerinin KDK değerleri üzerine etkisi (Tukey testi, p $\leq 0.05$ ). Table 7. Impact of treatments on CEC values of first and second vegetation soil samples (Tukey's test, $p \leq 0.05)$.

\begin{tabular}{|c|c|c|}
\hline \multirow{2}{*}{ Uygulamalar } & \multicolumn{2}{|c|}{ KDK (me $100 \mathrm{~g}^{-1}$ ) } \\
\hline & I.Vejetasyon & II.Vejetasyon \\
\hline 1 (NPK) & $2.55 \mathrm{e}$ & $2.37 \mathrm{e}$ \\
\hline 2 (4 t da ${ }^{-1}$ ahır gübresi+NPK) & $2.74 \mathrm{~b}$ & $2.47 c$ \\
\hline 3 (4 t da ${ }^{-1}$ kompost+NPK) & $2.65 \mathrm{~d}$ & $2.44 \mathrm{~cd}$ \\
\hline 4 (8 t da ${ }^{-1}$ kompost+NPK) & $2.70 \mathrm{c}$ & $2.45 \mathrm{~cd}$ \\
\hline 5 (Kontrol) & $2.41 \mathrm{f}$ & $2.30 \mathrm{f}$ \\
\hline 6 (4 t da ${ }^{-1}$ kompost) & $2.64 \mathrm{~d}$ & $2.43 \mathrm{~d}$ \\
\hline 7 (4 t da ${ }^{-1}$ ahır gübresi) & $2.70 \mathrm{c}$ & $2.51 \mathrm{~b}$ \\
\hline 8 (8 $\mathrm{t} \mathrm{da}^{-1}$ kompost) & $2.87 \mathrm{a}$ & $2.69 \mathrm{a}$ \\
\hline
\end{tabular}

\section{Verim}

Tüm uygulamalar biber bitkisinin verimini istatistiksel $(p<0.05)$ olarak arttırmıştır. Genel olarak verim değerleri incelendiğinde, en çok artışı ikinci vejetasyon döneminde (2015 ilkbahar) olduğu belirlenmiştir.
Denemenin birinci vejetasyon döneminde (2014 kış) meydana gelen aşırı soğuk ve kar sonucu verimde azalmalar görülmüştür. Maksimum toplam verim ise 2 numaralı (4 t da-1 ahır gübresi+ NPK) uygulamadan $2856 \mathrm{~kg} \mathrm{da}^{-1}$ olarak analiz edilmiştir (Şekil 1).

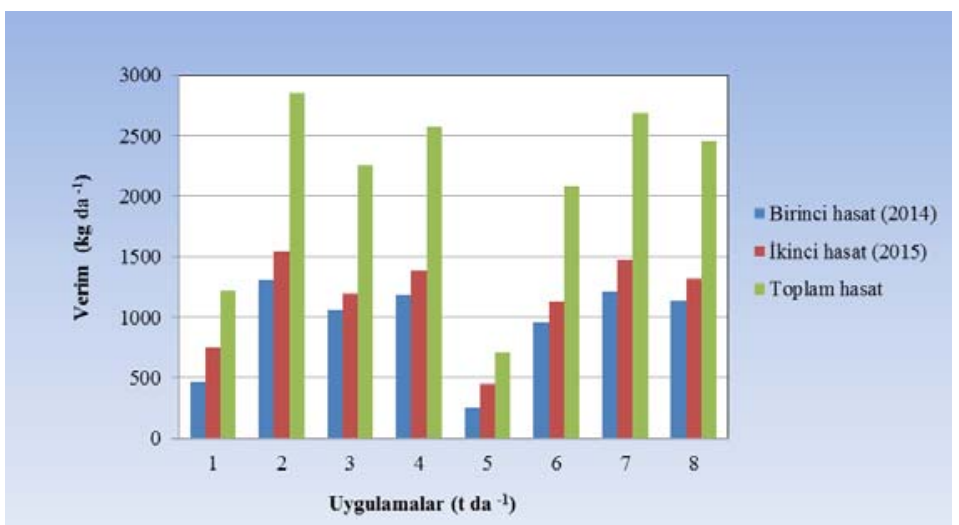

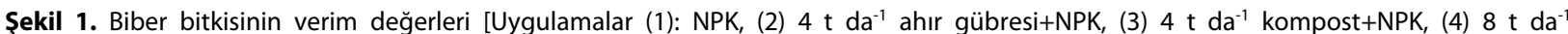
kompost+NPK, (5) Kontrol, (6) $4 \mathrm{t} \mathrm{da}^{-1}$ kompost, (7) $4 \mathrm{t} \mathrm{da}^{-1}$ ahır gübresi, (8) $8 \mathrm{t} \mathrm{da}^{-1}$ kompost] (Tukey testi, $p \leq 0.05$ ).

Figure 1. Pepper yield values [Treatetments (1): NPK, (2) 4 t da $a^{-1}$ farmyard manure+NPK, (3) 4 t da ${ }^{-1}$ compost+NPK, (4) 8 t da ${ }^{-1}$ compost+NPK,

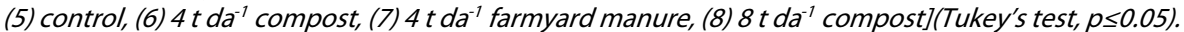


Ertekin (2002), cam serada ilkbaharda yetiştirilen biberden elde edilen verim değerlerinin $5 \mathrm{t} \mathrm{da}^{-1}$ olduğunu bildirmiştir. Ayrıca bitki verim değerlerinin, toprak bünyesine göre değiştiği birçok araştırmacı tarafından belirlenmiştir (Stone et al., 1985; Miller et al., 1988; Wright et al., 1990). Çerçioğlu (2006), tütün atığı ve ahır gübresi karışımlarının baş salata yetiştiriciliğinde toprak özellikleri ve verime olan etkileri ile ilgili yürüttüğü tez çalışmasında dekara 5 ton organik materyal uygulaması ile marul bitkisinin veriminde artışlar belirlemiştir. Marul verimi özellikle $\% 100$ tütün tozu kompostunun kullanıldığı parsellerde birinci ve ikinci hasat dönemleri toplamı $10.27 \mathrm{t} \mathrm{da}^{-1}$ olarak hesaplanmıştır.

$\mathrm{Bu}$ araştırmadan biber verimi ile ilgili elde edilen bulgular, literatürdeki sonuçlar ile uyumlu bulunmuştur. Ayrıca, çalışmada kullanılan organik madde içeriği yüksek bu materyallerin uygulanmasına paralel olarak verimde olumlu yönde artışlar sağlanacağı beklenen bir sonuçtur.

\section{SONUÇ}

Bitkisel atıklar veya agro-endüstriyel atıkların tarımda başarılı bir şekilde kullanılabileceği yapılan pek çok çalışma ile belirlenmiştir. Sera atıklarının ciddi bir organik madde kaynağı olmasının yanında içerdikleri bazı bitki besin maddeleri açısından da önemli bir potansiyele sahiptir. Seralardan elde edilen

\section{KAYNAKLAR}

Aydeniz, A. ve A. Brohi. 1991. Gübreler ve Gübreleme. C.Ü. Tokat Ziraat Fakültesi Yayınları No:10, Ders Kitabı:3, Tokat.

Bayındır, Ş., S. Şahin ve F. Uysal. 2004. Türkiye'de çiftlik gübresi kullanım potansiyeli. Türkiye III. Ulusal Gübre Kongresi TarımSanayi-Çevre, (11-13 Ekim 2004, Tokat) s. 735-743.

Benito, M., A. Masaguer, R. De Antonio and A. Moliner. 2005. Use of pruning waste compost as a component in soilless growing media. Bioresource Technology, 96(5): 597-603.

Benito, M., A. Masaguer, A. Moliner, and R. De Antonio. 2006. Chemical and physical properties of pruning waste compost and their seasonal variability. Bioresource Technology, 97(16): 20712076.

Bhattacharyya, P., K. Chakrabarti and A. Chakraborty. 2003. Residual effects of municipal solid waste compost on microbial biomass and activities in mustard growing soil. Archives of Agronomy and Soil Science, 49: 585-592.

Black, C.A. 1965. Methods of Soil Analysis, Part 1: Physical and Mineralogical Properties, including statistics of measurement and sampling. Agronomy Ser. 9. American Society of Agronomy, Inc. Publisher, Madison, Wisconsin, USA.

Bouyoucos, G.J. 1962. Hydrometer method improved for making particle size analysis of soils. Agronomy Journal, 54: 464-465.

Chang, J.I., J.J. Tsai and K.H. Wu. 2006. Composting of vegetable waste. Waste Management and Research, 24: 354-362. bitkisel atıkların kompostlaştırılarak değerlendirilmesi ile hem toprakların bitki besin maddesi ve organik madde miktarı önemli derecede arttırılarak kullanılan kimyasal gübre miktarı azaltılacak hem de yakılması sonucunda ortaya çıkan çevre kirliliği önlenmiş olacaktır.

Denemede kullanılan sera atığı kompostunun farklı dozlarının biber bitkisinin verimi ve toprağın kimyasal özellikleri üzerine olumlu bir etki sağlaması nedeniyle diğer organik gübrelere alternatif olarak kullanılabilecektir. Ancak bu kompostun değerlendirilmesinde kullanılacak olan atığın özelliğinin (içeriğinin) bilinmesi tarımsal üretimde başarı oranını daha da yükseltecektir. Atığın sahip olduğu özelliklere göre, belirli dozlarda toprağa uygulanarak kullanılması mümkün olabilecektir. Ayrıca çevreye gelişigüzel atılan ve çevre kirliliğine sebep olan bu atıklardan organik madde ve bitki besin maddesi kaynağı olarak yararlanılması ile ülke ekonomisine katkı sağlanmış olunacaktır.

\section{TEŞEKKÜR}

$\mathrm{Bu}$ araştırma, Dumlupınar Üniversitesi Bilimsel Araştırma Projeleri Komisyonu Başkanlığı (BAP) tarafından desteklenen 2014-16 no'lu projenin bir bölümüdür. Desteklerinden dolayı Dumlupınar Üniversitesi BAP birimine teşekkür ederim.

Çerçioğlu, M. 2006. Tütün atığı ve ahır gübresi karışımlarının baş salata (Lactuca sativa L. var. capitata) yetiştiriciliğinde toprak özellikleri ve verime olan etkileri. Ege Universitesi Fen Bilimleri Enstitüsü Yüksek Lisans Tezi.

Çıtak, S., S. Sönmez ve F. Öktüren. 2006. Bitkisel kökenli atıkların tarımda kullanılabilme olanakları. DERIM Batı Akdeniz Tarımsal Araştırma Enstitüsü, 23(1): 40-53.

Doran, J.W., D.G. Fraser, M.N. Culik and W.C. Liebhardt. 1987. Influence of alternative and conventional agricultural management on soil microbial process and nitrogen availability. American Journal of Alternative Agriculture, 2(3): 99-106.

Duman, İ. 2005. Biber Üretiminde İyi Tarım Uygulamaları Ders Notları. Ege Üniversitesi Ziraat Fakültesi Bahçe Bitkileri Bölümü, $11 \mathrm{~s}$.

Entry, J.A., B.H. Wood, J.H. Edwards and C.W. Wood. 1997. Influence of organic by-products and nitrogen source on chemica and microbiological status of an agricultural soil. Biology and Fertility of Soils, 24: 196-204.

Eriksen, J. 2005. Gross sulphur mineralisation-immobilisation turnover in soil amended with plant residues. Soil Biology and Biochemistry, 37(12): 2216-2224.

Erkoç, İ. 2009. Sera domates yetiştiriciliğinde kükürt ve leonardit uygulamalarının fosfor yarayıslılığına etkileri. Çukurova Üniversitesi Fen Bilimleri Enstitüsü Bahçe Bitkileri Ana Bilim Dalı Yüksek Lisans Tezi. 
Evliya, H., 1964. Kültür Bitkilerinin Beslenmesi. Ankara Üniversitesi Ziraat Fakültesi Yayınları No: 36, $446 \mathrm{~s}$.

Ertekin, U. 2002. Seracılık ve Örtüaltı "Biber, Domates, Hiyar, Patlıcan" Yetiştiriciliği. 505 s.

Jackson, M.L. 1967. Soil Chemical Analysis, Prentice-Hall of India Private Limited, NewDelhi.

Kacar, B. 1995. Bitki ve Toprağın Kimyasal Analizleri III: Toprak Analizleri. Ankara Üniversitesi Ziraat Fakültesi Eğitim Araştırma ve Gelişme Vakfı Yayınları No: 3, 705 s.

Kellogg, C.E. 1952. Our Garden Soils. The Macmillan Company, New York, p. 232.

Kütük, C., G. Çaycı, A. Baran, O. Başkan and R. Hartmann. 2003. Effects of beer factory sludge on soil properties and growth of sugar beet (Beta vulgaris saccharifera L.), Bioresources Technology, 90: 75-80.

Lindsay W.L. and W.A. Norvell. 1978. Development of a DTPA soil test for zinc, iron, manganese and copper. Soil Science Society of America Journal, 42: 421-428.

Madejon, E., R. Lopez, J.M. Murillo and F. Cabera. 2001. Agricultural use of three (sugar-beet) vinasse composts: Effect on crops and chemical properties of a Cambisol soil in the Guadalquivir river valley (SW Spain). Agriculture, Ecosystem and Environment, 84: 55-65.

Miller, M.P., M.J. Singer and D.R. Nielsen. 1988. Spatial variability of wheat yield and soil properties on complex hills. Soil Science Society of America Journal, 52: 1133-1141.

Nelson, D.W. and L.E. Sommer. 1982. Total carbon, organic carbon and organic matter. In: Methods of Soil Analysis, Part II: Chemical and microbiological properties. (Eds: A.L. Page, R.H. Miller and D.R. Keeney), American Society of Agronomy, Madison, WI, pp 539-579.

Olsen, S.R and E. L. Sommers. 1982. Phosphorous availability indices, phosporus soluble in sodium bicarbonate. In: Methods of Soil Analysis, Part II: Chemical and microbiological properties. 2nd ed. (Eds: A.L. Page, P.H. Miller and D.R. Keeney), American Society of Agronomy, Madison, WI, pp. 404-430.

Ozores-Hampton, M., T.A. Obreza and G. Hochmuth. 1998. Using composted wastes on Florida vegetable crops. HortTechnology, 8 (2): 130-137.

Özenç, N. 2004. Fındık zurufu ve diğer organik materyallerin fındık tarımı yapılan toprakların özellikleri ve ürün kalitesi üzerine etkileri. Ankara Üniversitesi Fen Bilimleri Enstitüsü Doktora Tezi.

Özgüven, M., Z. Kaya, A.M. Yılmaz, S. Kırıcı ve S. Tansı. 1996. Sigara fabrikası tütün atıklarının gübre olarak değerlendirilmesi. Turkish Journal of Agriculture and Forestry, 23(1): 43-51.
Pascual, J.A., M. Ayuso, T. Hernández and C.A. García. 1997. Phytotoxicity and fertilizer value of different organic materials. Agrochemical, 41: 50-62.

Randhawa, P.S., L.M. Condron, H.J. Di, S. Sinaj and R.D. McLenaghen. 2005. Effect of green manure addition on soil organic phosphorus mineralisation. Nutrient Cycling Agroecosystems, 73: 181-189.

Roe, N.E. and G.C. Cornforth. 2000. Effects of dairy lot scrapings and composted dairy manure on growth, yield, and profit potential of double cropped vegetables. Compost Science and Utilization, (8) 4: 320-327.

Röber, R. and K. Schaller. 1985. Pflanzenernährung im Gartenbau. Verlag Eugen Ulmer, Stuttgart.

Soil Survey Staff, 1951. Soil survey manual, USDA Agriculture Handbook 18, U.S. Government Printing Office, Washington, DC.

Stone, J.R., J.W. Gilliam, D.K. Cassel, R.B. Daniels, L.A. Nelson and H.J. Kleiss. 1985. Effect of erosion and landscape position on the productivity of piedmont soils. Soil Science Society of America Journal, 49: 987-991.

TÜiK, 2016. Türkiye İstatistik Kurumu, Örtü alt1 sebze ve meyve üretimi. http://www.tuik.gov.tr. Erişim: Ekim 2016.

Tüzel, Y., K. Boztok ve R.Z. Eltez. 1992. Atık kompostun kullanım olanakları. Türkiye IV. Yemeklik Mantar Kongresi (2-4 Kasım 1992, Yalova) Cilt 2, s. 1-10.

Tüzel, Y. 1996. Serada Ekolojik Tarım. (Ed: U. Aksoy ve A. Altındişli), Ekolojik Tarım Organizasyonu Derneği (ETO), Bornova, İzmir, s. 83-95.

Tüzel, Y. 2004. Ülkemizde seracılığın Gelişimi. V. Sebze Tarımı Sempozyumu (21-24 Eylül 2004, Çanakkale) Bildirileri, s. 13-18.

Tüzüner, A. 1990. Toprak ve Su Analiz Laboratuvarları El Kitabı. Tarım Orman ve Köy İşleri Bakanlığı Köy Hizmetleri Genel Müdürlüğü Yayın No: 279, 375 s.

USDA, 2002. Soil Electrical Conductivity Classification: A Basis For Site-Specific Management In Semiarid Cropping Systems. Agricultural Research Center, Lincoln. Nebraska.

U.S. Salinity Laboratory, 1954. Diagnosis and Improvement of Saline and Alkali Soils, USDA Handbook 60. U.S. Government Printing Office, Washington, DC, pp.1-160.

Wright, R.J., D.G. Boyer, W.M. Winant and H.D. Perry. 1990. The influence of soil factors on yield differences among landscape positions in an appalachian cornfield. Soil Science, 149: 375 382. 